\title{
Ensino superior, mídias e conhecimento: novas notícias e velhos discursos
}

\author{
Cezar Luiz De Mari
}

Lara Carlette Thiengo**

\section{Resumo}

A série de reportagens Universidade: a chave do futuro, exibida no mês de maio de 2011, no Jornal da Globo, é o recorte midiático que serve como ponto de partida para as discussões deste estudo. Apresentamos a análise de tal série entendendo que os meios de comunicaçáo atuam como porta-vozes do pensamento conservador brasileiro. O ferramental gramsciano norteia a análise ao situar as disputas ideológicas entre os grupos sociais na sociedade civil, representados pelos aparelhos privados de hegemonia, dentre os quais estáo os meios de comunicaçáo. $\mathrm{O}$ estudo perpassa pelas discussóes sobre o protagonismo da educação, sobretudo no atendimento às demandas do mercado e para o desenvolvimento, na estreita vinculação entre a educação e o setor econômico; a estrutura de tripé para a boa universidade; o binômio público e privado; bem como a avaliação e o ranqueamento das universidades. Tais temáticas em destaque expressam a constituição de um consenso conservador a respeito da reconfiguração do Ensino Superior no Brasil.

Palavras-chave: Ensino Superior. Meios de Comunicação. Gramsci, Antônio.

\footnotetext{
* Doutor em Educação pela Universidade Federal de Santa Catarina (UFSC). Professor do Departamento de Educação da Universdade Federal de Viçosa (UFV). Atua na Graduação e Pós-Graduação nas áreas de fundamentos da educação.

** Mestranda em Educaçáo no Programa de Pós-Graduação da UFV. Graduada em Comunicação Social - Jornalismo na Universidade Federal de Viçosa (UFV).
} 


\section{Introdução}

Em tempos de globalização, a mídia assegura sua centralidade na formação da mentalidade cotidiana, na medida em que o acesso ao "conhecimento" e às novas tecnologias digitais se difunde. A onipresença dos meios de comunicação e sua imanente exposição por meio da fabricação e mediaçâo de significados inauguram o que Rubim (2000) denomina "Idade Mídia", uma nova força nas relaçôes cotidianas entrecortando as diversas esferas sociais.

A globalização da mídia, que percorre o mesmo movimento das grandes corporações multinacionais, vai afirmando-se como uma espécie de intelecto coletivo das classes dominantes em todo mundo. No Brasil, também observamos que os interesses corporativos determinam pautas e eixos comunicativos na mídia a partir de conglomerados de meios de comunicação alinhados a grupos conservadores. A acelerada circulação de dados, conteúdos e redes que mediam o cotidiano cria condiçôes propícias para a reprodução instantânea dos discursos globais, legitimando os mecanismos de adequação aos consensos hegemônicos. Entendemos, assim como Moraes (2010), que a emergência da mídia global se dá sob a ideologia do "grandioso mundo sem fronteiras". Ianni (2000) considera a mídia atual como uma espécie de "príncipe eletrônico", que cria verdades virtuais, media interaçóes, recria interpretaçôes e realidades, além de simular autonomia de escolhas no consumo midiático, ou seja, potencializa a capacidade de configuração da sociabilidade hegemônica exercida pelos meios de comunicação.

Contudo, a expressividade da esfera comunicacional como mediadora das relaçôes sociais não é uma força tão nova assim, muito menos nasceu em decorrência exclusiva das novas tecnologias da informação. Gramsci (1999) é um dos autores que, já nas décadas de 1920 e 1930, escrevia sobre a relevância dos meios de comunicação, notadamente dos jornais e do rádio, entendendo sua função orgânica no processo de produção ideológica e na construção da hegemonia.

O embate pela hegemonia pressupóe a conquista do consenso e da liderança cultural, o que se dá nos planos político, econômico e cultural, utilizando-se de formas coercitivas e consensuais na sociedade política e na sociedade civil. A sociedade política é o conjunto de mecanismos pelo qual a classe dominante exerce poder, o monopólio legal da repressão e da violência, ou seja, o aparato coercitivo e a aplicação das leis. A esfera civil designa o conjunto 
de instituiçóes responsáveis pela elaboração e difusão das ideologias, como o sistema escolar, a Igreja, os partidos políticos, os meios de comunicação, entre outros, também chamados de aparelhos privados de hegemonia (GRAMSCI, 1999).

De acordo com Gramsci (1999), as classes dominantes produzem o consenso organizando as esferas sociais de acordo com as tendências materiais e ideológicas derivadas em senso comum, que se confunde com a própria cultura hegemônica, na qual os valores são incorporados como naturais. Arroyo (2005), à luz de Gramsci, compreende o senso comum como amálgama de uma ideologia dominante e diversas ideologias tradicionais que formam uma visão de mundo conforme a posição cultural e social dos indivíduos. O senso comum redundará das disputas entre os grupos sociais, cujas capacidades de manifestações são diversas e dependentes de sua posição social. Os grupos sociais estáo imersos na cultura dominante que lhes fornece instrumentos de construçáo e de fortalecimento das identidades, criando e alimentando símbolos, mitos e estereótipos. As tendências hegemônicas se expressam no curso natural, enquanto os processos de resistência nascem e são elaborados a partir das contradiçôes sociais.

Gramsci (2005), ao considerar o papel de destaque dos meios de comunicação na arena de disputa hegemônica - ou seja, a sociedade civil como aparelho privado de hegemonia -, criticava o alinhamento ideológico dos jornais ao poder, bem como o controle do noticiário e da opiniāo, ainda que camuflados em recortes simplistas e conformistas.

Sendo assim, utilizaremos o pensamento gramsciano como aporte teórico na construção deste artigo, pela sua atualidade quanto ao entendimento das funçôes dos aparelhos privados de hegemonia em uma sociedade de classes.

Buscando entender o papel mediador das mídias na sua relação com a educação, neste estudo, utilizaremos um recorte discursivo considerando as produçóes da mídia brasileira - a série televisiva Universidade: a chave do futuro - para compreender e analisar a produção do senso comum sobre o Ensino Superior brasileiro. A série analisada foi exibida pelo Jornal da Globo ${ }^{1}$ entre os dias 23 e 27 do mês de maio de 2011, sendo cinco reportagens apresentadas com o objetivo, do ponto de vista de seus interlocutores, de traçar um panorama do Ensino Superior na atualidade, apontando tendências e problemas. Ao trabalhar com tal investigação, presumimos que tais discursos produzem significados por meio de suas linguagens, operando no entendimento da Educação Superior 
e instituindo maneiras de pensar sobre ela. As reportagens que compõem a série são:

- Série especial mostra desafios no crescimento do Ensino Superior: "Universidade: a chave do futuro" mostra como está a estrutura das universidades para formar um número crescente de brasileiros que ingressam no Ensino Superior;

- Pesquisadores de universidades falam da burocracia para trabalhar: a pesquisa no País é vítima também de um sistema que não privilegia o mérito. Pesquisadores contam a luta contra as complicaçôes para desenvolver suas atividades;

- Universidades brasileiras possuem deficiências graves na estrutura: no tripé que faz uma boa universidade, professor-estrutura-aluno, o Brasil tem problemas nos três. Exemplos de abandono, professores sem motivação e alunos que vão aprender na faculdade o que faltou no Ensino Médio;

- Universidades americanas estáo entre as melhores instituiçóes do mundo: os Estados Unidos costumam ter seis ou sete instituiçôes entre as dez melhores. E, entre as cem melhores, não aparece uma única universidade brasileira; $\mathrm{e}$

- Universidades driblam burocracia e produzem pesquisas surpreendentes: mesmo respirando burocracia e desprezando o mérito, algumas universidades brasileiras conseguem produzir pesquisas excelentes. Conheça o Instituto Natal de Neurociências, no Rio Grande do Norte.

Este estudo é organizado de acordo com alguns eixos, sendo eles: centralidade da educaçáo $\mathrm{x}$ atendimento de demanda do mercado; tripé para a boa universidade; setor público x setor privado; e avaliação e ranqueamento.

\section{Centralidade da educação $\mathrm{x}$ atendimento da demanda do mercado: o conhecimento no eixo econômico}

Universidade: a chave do futuro (UNIVERSIDADE, 2011), título da série, já anuncia a centralidade do Ensino Superior na ligaçáo entre universidade e desenvolvimento econômico, calcada em uma ideia de modernidade e 
adequação a uma "sociedade do conhecimento" ou, ainda, a uma "economia do conhecimento"2.

Este eixo remete ao peso da construçáo da sociedade civil e do aspecto salvífico dado à Educação Superior brasileira, sobretudo às universidades, a partir da década de 1990, como podemos perceber na fala do professor responsável pelo Instituto de Neurociências apresentado na série: "[...] educação é a raiz da construção de uma sociedade civil. É o que traz a seiva que faz essa sociedade civil crescer ou abortar" (UNIVERSIDADE, 27 maio 2011).

Neste viés, a ideia de desenvolvimento torna-se ainda mais aproximada à de educação, uma vez que o conhecimento e sua aplicação são lidos como fatores do desenvolvimento econômico. O Ensino Superior passa a assumir, nesse novo cenário, um papel de construtor da "sociedade do conhecimento", sendo responsável por demandas de conhecimentos imediatamente vinculados ao mundo do trabalho. O que se confirma na fala sobre o egresso: "[...] o perfil do nosso egresso é uma pessoa que esteja voltada pra imediata inserção no mercado de trabalho" (fala do coordenador de engenharia da Estácio de Sá, Jorge Luís da Rocha apud UNIVERSIDADE, 23 maio 2011).

A Educação Superior parece ganhar seu "sentido de ser" apenas no campo de produção de conhecimento aplicado, tendo sua problemática localizada entre a articulação da qualidade dos conhecimentos solicitados pela sociedade e a qualidade do conhecimento produzido nas universidades. O que se chamava de "educação terciária", como observado na larga literatura produzida ao longo da década de 1990, agora surge como discurso generalizante para toda a formação universitária ${ }^{3}$. Essa literatura explicita como as demandas sociais pragmáticas condicionam uma concepção específica de formação para os campos técnico, profissionalizante e virtual, uma vez que se torna necessário o fomento de uma cultura empresarial produtora de maior número de postos de trabalho precários. Essa tendência se verificou em um trecho da série, na qual podemos inferir o esforço de legitimação da ideia de diferenciação na formação a um mercado flexível, indicada em termos de atendimento àquela parcela da população de baixa condição socioeconômica. "Nós temos que, na verdade, atender a uma variedade maior de estudantes com vocaçóes diferentes e que se encaminhem pra vida com multiplicidades de novas ocupaçóes que estão sendo criadas a cada dia" (pesquisadora da Universidade de São Paulo Eunice Ribeiro Duraham apud UNIVERSIDADE, 23 maio 2011). 
Sob uma perspectiva histórica, é possível localizar a origem da escola dentro da sociedade de classes, uma vez que, existindo uma classe ociosa, surge uma educação diferenciada. Segundo Saviani (1994, p. 152), “[...] a palavra escola em grego significa o lugar do ócio". A educação, até o século XIX, mantinha-se como espaço de formação das classes dominantes. Com o advento do industrialismo moderno, a escola passa a exercer um papel mais amplo na instrução da classe trabalhadora em função das novas necessidades sociais.

A escola está associada ao progresso, à aquisição de hábitos civilizados, políticos, no sentido de formar sujeitos que exerçam seus direitos e deveres na sociedade moderna, centrada na cidade e na indústria. Com isso a escola torna-se a agência educativa dominante da moderna sociedade, a tal ponto que a forma escolar passa a ser considerada e confundida com a educaçáo propriamente dita. Mas esse papel que ao mesmo tempo é abrangente demonstra o caráter contraditório da escola. No momento em que a sociedade capitalista preconiza a generalização da educação escolar básica, ela reconstitui a diferença entre as escolas para as massas, que se limitam à educação básica ou, quando muito, prosseguem estritamente a habilitaçôes profissionais, e as escolas de elite, destinadas estritamente à formação intelectual, daí a frase famosa atribuída a Adam Smith (1883): "Instrução para os trabalhadores, porém em doses homeopáticas", quer dizer, um mínimo de instrução para que desempenhem seu papel na sociedade capitalista, mas que ao mesmo tempo não ultrapassem a segurança para a manutenção da ordem social (SILVA, 2011, p. 90).

Assim, o ensino como resposta social ao industrialismo representou o eixo onde se desenvolveu a escola moderna interessada. Gramsci (1999), analisando as tendências da reforma da escola italiana no início do século XX, questionava o caráter reduzido que possuía a formação profissionalizante ao criar uma ideia de democracia que, ao contrário, tendia a eternizar as diferenças e solidificar a degenerescência progressiva da escola.

Atualmente, a indústria aguarda que a universidade cumpra o papel de formadora de mão de obra, sob o viés do conhecimento tecnológico. A indicação 
da série insinua que as universidades não estão formando adequadamente, por isso, o desemprego dos jovens.

[...] no setor industrial, por exemplo, $69 \%$ das empresas têm dificuldade para encontrar profissionais qualificados e se for comparar o Brasil com uma indústria, é como se máquinas estivessem à espera de alguém que saiba usá-las para multiplicar a produção. E se os universitários não preenchem as vagas é por falta de qualidade no Ensino Superior (UNIVERSIDADE, 23 maio 2011).

A tendência da aproximação entre empresa e universidade aparece na fala acima, assinalando por onde passa o pensamento hegemônico divulgado pela mídia. Gramsci já apontava as deficiências desse tipo de educação na formação e propunha abolir as escolas do tipo interessadas, instrumentais, partindo para a formulaçáo de uma escola que propiciasse o desenvolvimento das potencialidades técnicas e intelectuais, uma formação completa do homem, a "Escola Unitária". Esta escola teria como eixo de formação a "omnilateralidade", que consiste na práxis educativa dentro de uma concepção de formaçáo que sintetiza as tendências mais avançadas do industrialismo e, também, a formação para a universalidade.

\section{O tripé para a boa universidade}

$\mathrm{Na}$ segunda reportagem da série, Universidades brasileiras possuem deficiências graves na estrutura (UNIVERSIDADE, 2011), é apresentado o tripé professor-estrutura-aluno como fundamento para uma universidade de qualidade. No Brasil, de acordo com o veiculado, as universidades públicas têm deficiências nos três itens, elencando exemplos de estruturas inadequadas, falta de motivação dos professores e alunos despreparados.

O Laboratório de Pesquisas Farmacêuticas da Universidade Federal de Maranhão (UFMA), que está fechado há mais de uma década, é utilizado como exemplo do descaso, falta de estrutura e comprometimento com a formação dos estudantes. No Laboratório de Bioquímica da mesma universidade, também é verificada a falta de infraestrutura, manutenção, equipamentos e funcionários. Ainda nessa lógica, são apresentadas outras universidades com problemas semelhantes, destacando-se que os problemas não são apenas estruturais. $\mathrm{O}$ 
descaso com os professores universitários também foi explicitado, uma vez que a estabilidade do emprego é colocada como um empecilho ao incentivo à carreira docente, apontando que a valorizaçáo do professor, de acordo com um sistema de mérito, seria mais bem adequada. O que se compreende por sistema de mérito se encaixa no conceito econômico do custo-benefício, em que o trabalho docente na universidade é compreendido pelo viés produtivo. Por conta disso, observamos a passagem abaixo, em que se critica a burocracia (leia-se, universidade pública com dedicação exclusiva) e incentiva-se o mérito (leia-se produção por resultados):

Pesquisa é o que se espera que ocorra numa universidade, mas a pesquisa em universidade brasileira é refém da burocracia e vítima também de um sistema que não privilegia o mérito. É inaceitável que o professor que está sendo remunerado a dar essa aula simplesmente não aparecer pra dar aula (fala do especialista Gustavo Ioschpe).

Os estudantes também são colocados como um importante fator do tripé para uma boa universidade, mas também apresentados em dimensão problemática, uma vez que a reportagem enfatiza o despreparo desses alunos ao chegarem ao Ensino Superior, o que dificulta o desenvolvimento da aprendizagem e, consequentemente, a formação profissional deles: "[...] a deficiência do aluno vem do Ensino Médio. Vem de uma realidade muito aquém da realidade onde não conseguiu captar todas as informaçóes do Ensino Médio" (UNIVERSIDADE, 24 maio 2011).

Assim, apesar de retratar situaçóes reais de descaso e falta de infraestrutura, a reportagem enfatiza um discurso generalizante de ineficiência das universidades públicas, entendendo-as como instituições de baixa contribuição para a sociedade. Ao discutir as deficiências, tanto da universidade quanto dos alunos, não são apontadas as causas de sua origem. A generalização funciona como forma de "passar ao largo" da verdadeira condiçấo de desequilíbrio existente na formação dos Ensinos Fundamental e Médio das escolas públicas e privadas.

Para Gramsci (2000a, p. 189), “[...] a universidade tem a tarefa humana de educar os cérebros para pensar de modo claro, seguro e pessoal". Ainda que o autor não restrinja a formação universitária - sendo esta, segundo ele, também realizada em toda a sociedade -, enfatiza o papel relevante da universidade 
nessa formação. A escola é, portanto, se bem utilizada, o instrumento pelo qual os vários níveis de intelectuais podem ser elaborados, uma vez que é por meio desta que o homem desenvolve sua capacidade intelectiva, aprende a relacionar-se com o meio de forma sistemática e crítica, abrindo seus horizontes intelectuais e ampliando sua perspectiva social. Desse modo, a escola é o meio privilegiado para a manutenção ou mudança de ideologias hegemônicas que estruturam a sociedade.

\title{
Setor Público x Setor Privado: entrave/integração universidade e empresa
}

A questáo do binômio público e privado no setor educacional pode ser compreendida desde as origens da popularização do ensino brasileiro. $\mathrm{O}$ ataque ao setor do ensino público foi incentivado, ao longo da década de 1990 e com mais intensidade, sob os auspícios do neoliberalismo. A partir do governo Luiz Inácio da Silva (2002-2010), um clima de otimismo foi instaurado, principalmente, com a construção discursiva que privilegia exemplos de cidadãos de baixa condiçấo econômica e social que conseguiram cursar o Ensino Superior. Os exemplos trazidos reproduzem a ideia otimista sobre a ampliação do Ensino Superior, sob a lógica da igualdade de oportunidades, reforçando uma ideia de desenvolvimento e melhores condiçóes. Dessa forma, as histórias de vida são utilizadas como estratégia de identificação e sensibilização, na medida em que os expectadores "se enxergam" nas situaçôes descritas, contribuindo para a construção de um senso comum sobre a temática.

\begin{abstract}
"Começou assim: eu trabalhava em obra, trabalhava como servente, lavando banheiro químico", conta o estudante de engenharia Franklin Salvador. Mesmo depois do supletivo, do curso técnico e da promoção, Franklin achava impossível subir ao mundo dos doutores e bacharéis. "Faculdade, universidade, eu nem pensava, jamais, eu pensava que não era pra mim, pensava que era pra filhinho de papai”. Mas aquele era outro Brasil. Depois que a economia deu um salto, milhóes de brasileiros descobriram na universidade o melhor caminho para continuar subindo. Ergueram-se escolas gigantes (UNIVERSIDADE, 23 maio 2011).
\end{abstract}


Não obstante a importância da ampliação de vagas no Ensino Superior realizada pelo governo Lula, a apropriação midiática desta precisa ser analisada. O sentido explorado por ela reforça a mentalidade de que a formação tenha um cunho eminentemente voltado ao trabalho. Tal apropriação diz respeito ao esforço da classe dominante em tornar a educação uma mediação de seus interesses num mercado volátil e confuso.

Uma concepção ingênua da objetividade (CHALMERS, 1993), combinada com a preocupação evidenciada pelo estilo jornalístico em tornar as narrativas facilmente compreensíveis e reconhecíveis, tem como consequência a produção de narrativas que acentuam o conformismo e não proporcionam ação reflexiva ou crítica por parte dos receptores da mensagem. A naturalidade com que os fatos, ainda que promovidos como espetáculo, são apresentados contribui para a constituição de um senso comum no que se refere ao Ensino Superior brasileiro ${ }^{4}$.

Assim, de acordo com os dados do MEC/INEP (BRASIL, 2010), havia 245 Intituiçóes de Ensino Superior (IES) públicas e 2.069 IES privadas. Apesar do crescimento das IES públicas entre 2008 e 2009, as IES privadas somam $89,4 \%$ do total das instituiçóes de Ensino Superior. Desse modo as instituiçóes privadas atendem ao maior contingente de estudantes. A organização acadêmica definidora do perfil do Ensino Superior brasileiro continua sendo a faculdade, representando $85 \%$ das instituiçôes. Esses dados indicam muito daquilo que buscamos dizer ao longo deste estudo, especialmente em relação ao perfil do egresso e das instituiçôes marcadas pela aproximaçấo do Ensino Superior às demandas industriais.

$\mathrm{Na}$ reportagem, o Ensino Superior privado é apresentado como o setor que abarca um maior número de estudantes e que, entretanto, trabalha com um perfil de público diferenciado, em que mais de $90 \%$ dos estudantes já está inserido no mercado de trabalho, o que compromete a assiduidade e o rendimento deles. Apesar dessa condição, a análise apresentada pela série aborda, no plano micro, um importante avanço em termos de acesso ao Ensino Superior das pessoas de classe popular. O elemento central desse discurso, que é apropriado pela série de reportagens, recai sobre o eixo identificador do fato com a população mais simples.

No dia da formatura, ele diz: "Eu fui o único da minha família a conseguir um diploma do Ensino Superior". E com certeza nós mudamos a história daquele aluno, 
ele vai poder dar melhores condiçóes para sua família e provavelmente seus filhos farão a universidade mais cedo (UNIVERSIDADE, 23 maio 2011).

O posicionamento crítico em relação à expansão das universidades também é apresentado pela série, ainda que rebatido em sequência, uma vez que problematiza apenas o valor das mensalidades, e não a qualidade das instituiçôes e a minimização do papel do Estado na gestấo do Ensino Superior.

"Shopping centers de ensino!" - gritam os críticos. Sim, existe clima de liquidação. $\mathrm{O}$ valor das mensalidades está muito alto nas últimas décadas. Mas é consenso no setor que as faculdades precisam crescer e devem cumprir o papel de preparar os jovens para o mercado de trabalho. $\mathrm{O}$ que a universidade contribui para mover a economia de um país é a boa educação que ela faz pros estudantes, diz diretor científico da Fapesp, Carlos Henrique de Brito Cruz (UNIVERSIDADE, 23 maio 2011).

Compreendemos que é preciso situar os limites do avanço das vagas no Ensino Superior, uma vez que o enfoque somente no acesso prejudica o entendimento mais complexo das reais condiçóes da própria classe trabalhadora quanto aos problemas da permanência, da tendência aplicada do conhecimento e a indústria de diplomas vinculada ao Ensino Superior brasileiro. A ampliação do acesso na configuração atual vem acompanhada da justificativa de uma formaçáo aligeirada e imediatamente aplicada, como explicita o repórter: "[...] se o Brasil tem pressa para crescer, tem urgência na formação de profissionais. Será que as nossas escolas estáo formando corretamente? Qual o papel da universidade?" (UNIVERSIDADE, 23 maio 2011).

Nesse sentido, encontramos na série de reportagens um discurso que compreende o público na relação com a empresa e no questionamento sobre a função da universidade no quadro atual do desenvolvimento. $\mathrm{O}$ exemplo da relação universidade/empresa vem do Instituto de Neurociências, cujo foco de uma das reportagens da série busca mostrar como pesquisas "surpreendentes" podem ser feitas quando são estabelecidas parcerias público-privadas.

Uma estrada no meio do nada. Levando pra onde? Aqui no semiárido nordestino, se construiu o que pode 
ser uma parte fundamental pro futuro da pesquisa científica no Brasil. Depois da ampliação o Instituto de Neurociências vai abrigar 45 laboratórios, sendo o maior do País, exemplo de parceria entre a iniciativa privada e o governo federal, que entrou com 50 milhóes de reais (UNIVERSIDADE, 27 maio 2011).

Outro exemplo das chamadas "ilhas de excelência" é a Coppe/ UFRJ, que produz tecnologia de ponta no campo de exploração das profundezas do mar.

A Coppe surgiu nos anos de 1960 para abrigar a PósGraduação do curso de Engenharia da Federal do Rio, virou uma ilha de excelência, principalmente porque as parcerias com empresas deram injeções de dinheiro e agilidade. Um prédio inteiro e 55 pesquisadores dedicados a entender as profundezas são só uma parte do que tem sido feito, e colocando o Brasil, pelo menos neste segmento à frente da concorrência mundial (UNIVERSIDADE, 27 maio 2011).

De acordo com Nairdof (2005), a reprodução da ideia de ineficiência do setor público está ligada a outro conceito, que é o de "reprivatização". Este, por sua vez, está relacionado à mutação do conceito de educação, que passa de direito à condição de bens e serviços, para então ser considerada quase um "dever", de responsabilidade individual. E talvez o lado mais complexo deste conceito seja exatamente a ideia de tornar os setores público e privado indistintos do ponto de vista da pesquisa, ou seja, ambos produzindo em função da empresa, com o aporte público.

De acordo com essa perspectiva de "privatização do conhecimento", diversos agentes vinculados ao campo científico-tecnológico das universidades têm sido convencidos a adequar suas atividades ao setor produtivo. A concepção de privatização do conhecimento é tomada em um sentido amplo, o que significa que o conhecimento gerado em âmbitos públicos com financiamento privado incorpora termos de confidencialidade que limitam o seu livre fluxo. Da mesma forma, seleciona temas de investigação mais rentáveis, valorizando o trabalho acadêmico de acordo com a lógica empresarial. Nesse sentido, mescla uma combinação de pressão do mercado e maior controle do Estado, formulando um pacote no qual encontramos as "universidades comerciais" e as 
"universidades controladas". Nessa perspectiva, a universidade se caracteriza pela ampliação das instituiçôes de Ensino Superior privadas, programas orientados de acordo com as clientelas específicas, racionalidade corporativa, flexibilização do trabalho docente, intensificação das relações com as empresas, enquanto as universidades controladas pelo Estado têm recortes de financiamento público, restrições na concessão de fundos e na tentativa de normalização, coordenação e controle de políticas.

\section{Avaliação e ranqueamento: as melhores e as piores universidades}

"Está se incorporando nas públicas e nas privadas essa cultura de avaliação", afirma o secretário de Ensino Superior do MEC, Luiz Cláudio Costa (UNIVERSIDADE, 23 maio 2011). No que diz respeito à avaliação do ensino, o Estado assume a responsabilidade por realizá-la. De acordo com Afonso (2003), em decorrência da globalização, as mudanças nas relaçóes sociais também passaram a determinar uma nova configuração do papel do Estado como competidor e, consequentemente, como avaliador. Segundo Dale (2004), esse Estado competidor pode atuar na promoção da investigação para as forças produtivas, bem como para os mecanismos de mercado na educação ou, ainda, para a utilizaçáo da educação como forma de produzir mão de obra especializada, de acordo as orientaçóes do Banco Mundial.

$\mathrm{Na}$ série, além de uma lógica de avaliação interna (do País), insere-se um discurso referente às formas de ranqueamento em padróes globais, em que os Estados Unidos são apresentados como exemplo a ser seguido, uma vez que "[...] os EUA costumam ter seis ou sete escolas entre as dez melhores. Enquanto que, entre as cem melhores, não aparece nenhuma universidade brasileira" (UNIVERSIDADE, 26 maio 2011). São elencados como pontos principais para tal distinção entre os dois países: a diversidade de estudantes, a assistência estudantil, o recrutamento de "inteligência" e o avanço tecnológico das instituiçóes; constatando significativa inferioridade das universidades públicas brasileiras em relação às estadunidenses.

Na USP, 2\% de estrangeiros. Na maior pública norteamericana, 37\%. Estamos muito entusiasmados com a 
diversidade. Entendo que a educação deve ser feita mesmo assim. Ele acha possível porque as grandes universidades americanas adotam o processo cego de admissão. Assim, eles não sabem a origem socioeconômica dos futuros alunos, enquanto processo seletivo. O que importa é trazer para estas universidades os melhores cérebros do mundo e manter estas escolas entre as melhores do mundo. Em Harvard, a Biblioteca já nasceu com o objetivo de acabar, todos os livros serão digitalizados. Enquanto, no Brasil, temos bibliotecas com livros antigos (UNIVERSIDADE, 26 maio 2011).

As reportagens ainda trazem exemplos de brasileiros que vão estudar no exterior, custeados por grandes universidades. "Por que perdemos estes talentos?" é a pergunta colocada pelo repórter. A resposta dos estudantes está baseada em melhores oportunidades de pesquisa e de salário nos Estados Unidos, além da assistência estudantil. A reportagem é finalizada contando a história de um brasileiro financiado integralmente nos EUA: "[...] lá se vai o futuro matemático com emprego garantido sem data para voltar" (UNIVERSIDADE, 26 maio 2011).

Ainda sob a lógica de ranqueamento, temos observado recentemente o projeto "Top 200", incentivado pelo MEC, para entrada de universidades brasileiras no ranking das 200 universidades mais importantes do mundo 5 . Tratase de localizar, do ponto de vista do ranqueamento atual, o Brasil no campo das grandes universidades mundiais. Em relação ao eixo orçamentário de incentivo do MEC, o foco recai, exclusivamente, sobre os cursos que produzem inovação e tecnologia ${ }^{6}$. E, talvez, o mais importante para o objetivo deste artigo seria ressaltar que, entre os treze critérios para a escolha das “Top 200", encontra-se a relação entre a universidade e a indústria.

\section{Considerações finais}

Consideramos que a série de reportagens Universidade: a chave do futuro (UNIVERSIDADE, 2011) pode ser entendida como produto dos veículos de comunicação que atuam como porta-vozes do pensamento conservador, uma vez que contribui para a construção de um consenso a respeito do papel da Educação Superior em uma "nova sociedade", uma sociedade/economia do conhecimento ${ }^{7}$. 
Esta tendência vem sendo discutida e implementada no Brasil desde a década de 1990 e é sustentada, de acordo com Velloso (2002), pelo argumento que os países desenvolvidos já estão, hoje, voltados para uma economia do conhecimento e que "[...] países emergentes, como a Coreia e a China, já têm programas nacionais para desenvolver a economia do conhecimento" (VELLOSO, 2002, p. 11). Logo, o Brasil não pode "ficar para trás", sendo necessários "[...] progressos em ciência e tecnologia, educação, avanço das exportaçôes" (VELLOSO, 2002, p. 11).

Percebemos a materialização nas ações governamentais matizadas nas ideias de globalização, modernidade e avanço tecnológico, determinadas como o "caminho para o progresso". Várias dessas "orientaçôes" podem ser verificadas em esforços governamentais na última década, como a criação de mecanismos para o avanço da tecnologia, por meio de incentivos à inovação tecnológica, ampliaçáo do acesso às tecnologias da informaçáo; produçáo de softwares; aproximaçáo entre a universidade e a empresa; programas de ampliaçáo do número de incubadoras de empresas nas universidades; e ampliação de políticas educacionais voltadas para o modelo de competências e educação ao longo da vida.

Nesse primeiro ano do governo Dilma, porém, podemos observar algumas orientaçôes que destoam dos discursos "progressistas" acima descritos. Do corte de R \$ 50 bilhōes no Orçamento anunciado pela equipe econômica do governo, R\$ 1 bilhão deverá vir do Ministério da Educação (MEC), do qual uma parte da conta ficará para as universidades federais. A orientação para estas está sendo no sentido de avaliar as possibilidades de cortar $10 \%$ dos recursos para custeio, como água, luz e assistência estudantil, além de 50\% do dinheiro destinado a diárias e passagens.

Quanto aos concursos de professores e técnicos - que não serão realizados no prazo médio de dois anos -, estes serão substituídos por contrataçóes temporárias de professores e técnicos de nível superior. No entanto, os IFETs não seguirão a mesma lógica. $\mathrm{O}$ Ministério do Planejamento autorizou a realização de seleçóes para preencher 4.683 vagas nos Institutos Federais de Educação, Ciência e Tecnologia de todo o Brasil. Dessas, 2.867 são para o cargo de professor da carreira de Educação Básica, Técnica e Tecnológica, e 1.816, para a de servidor técnico-administrativo. Tal medida é justificada pela necessidade de dar continuação ao projeto de expansão da rede de ensino profissionalizante, iniciada em 2002. De 1999 a 2002, foram construídas 140 escolas técnicas no 
Brasil. Nos oito anos da gestáo do governo Lula, foram entregues 214 unidades. Já a presidente Dilma Rousseff quer construir mais cem escolas e concluir outras 81 iniciadas no governo anterior.

Desse modo, compreendemos que o tratamento diferenciado para com os IFETs é uma estratégia governamental sustentada pela necessidade de "profissionais qualificados" para impulsionar o "desenvolvimento do País", nos permitindo ratificar apontamentos já feitos no decorrer deste estudo, como a educação como promotora do desenvolvimento; ênfase nos cursos tecnológicos; e capacitação profissional atrelada à ideia de técnica. Assim, podemos inferir que o discurso sobre a educação vem sendo redesenhado diante das novas necessidades do mercado, no qual se reconhece a centralidade do Ensino Superior, na acepção elástica, envolvendo universidades, cursos técnicos e novas modalidades de ensino.

A série Universidade: a chave do futuro (UNIVERSIDADE, 2011) sintetiza, a nosso ver, as orientaçóes conservadoras sobre a educação, apontando os problemas das universidades e a necessidade de novas alternativas para a melhor gestão do setor, enfatizando a lógica das competências e, consequentemente, o esvaziamento teórico na formação humana, sublinhada por concepçóes teórico-práticas que se materializam na produção do consenso conservador, assim expresso: "está é a melhor e a única sociedade possível".

Por fim, ainda que os conglomerados midiáticos sejam predominantes na sociedade civil, atuando em prol da disseminação de ideologias conservadoras que ratificam a naturalização do capitalismo sob o discurso da globalização e da modernidade, é importante salientar as consideraçóes de Gramsci a respeito da possibilidade de atuação dos aparelhos privados de hegemonia em dissonância com os valores do capital vigentes. Pois a conquista do poder deve ser precedida por sucessivas batalhas pela hegemonia e pelo consenso no interior do Estado em sentido amplo e propóe uma longa marcha através das instituiçóes sociais (GRAMSCI, 2000b). Antes de ser encarcerado, entre 1910 e 1926, Gramsci escreveu mais de 700 artigos em jornais operários da Itália, desenvolvendo a prática jornalística em favor da contestação de sua realidade, entendendo não apenas a dimensão político-econômica no processo revolucionário, mas também a dimensão cultural. 


\section{Notas}

1 Partimos do entendimento de que, na realidade brasileira, a televisão tem papel central. Tecnicamente, ela é um meio de comunicação que se destina a um público anônimo, heterogêneo e se caracteriza pela veiculação de imagens, sons e textos de forma fragmentada e inserida em um fluxo contínuo de conteúdos e gêneros diversificados.

2 Em pelo menos dois momentos na série de reportagens, a expressão "sociedade do conhecimento" foi utilizada como conceito para fundamentar a aproximação da universidade à empresa.

3 Referimo-nos aos documentos do Banco Mundial elaborados para orientar as reformas das políticas educacionais dos países em desenvolvimento.

4 O conteúdo jornalístico atual, em grande parte, pode ser percebido como oposto ao conceito de jornalismo apontado como ideal por Gramsci, o Jornalismo Integral (jornalismo não apenas para atender às necessidades de uma categoria, mas sim, que, de forma engajada, desenvolve necessidades em seu público). Este entende todos os lados da situação, não apenas noticia, mas dissemina seu arsenal crítico, aguçando ou "educando" seu público.

5 A USP, segundo o ranking 2011, está posicionada em 178º, conforme ranking de universidades da Times Higher Education (THE).

6 O que pode ser conferido no edital lançado recentemente com o título Ciência sem fronteiras.

7 É importante evidenciar que não entendemos este processo de disseminação ideológica como natural e rápido. Para Gramsci, a construçáo das formas de pensar, nas crenças e opinióes e até mesmo a modificação destas não acontecem de forma repentina, mas sim na medida em que ocorrem "combinaçóes sucessivas". O autor ainda destaca que um mesmo pensamento homogêneo difundido pode não ser abstraído da mesma forma pelos diferentes receptores, uma vez que nem todas as classes sociais elaboram a sua cultura e sua consciência da mesma forma. 


\section{REFERÊNCIAS}

AFONSO, Almerindo Janela. Estado, globalização e políticas educacionais: elementos para uma agenda de investigação. Revista Brasileira de Educação, n. 22, jan./abr. 2003.

ARROYO, Mariela. Concepciones del espacio público y sentido común en la educación superior. In: GENTILI, Pablo; LEVY, Bettina (Org.). Espacio público y privatización del conocimiento: estudios sobre políticas universitarias en la América Latina. Buenos Aires: Clasco, 2005. p. 27-100.

BRASIL. Ministério da Educação. Instituto Nacional de Estudos e Pesquisas Educacionais. Resumo técnico: senso da educação superior de 2009. Brasília, DF, 2010. Disponível em: <http://download.inep.gov.br/download/superior/ censo/2009/resumo_tecnico2009.pdf>. Acesso em: nov. 2011.

CHALMERS, Alan F. O que é ciência afinal? Tradução de Raul Filker. São Paulo: Brasiliense, 1993.

DALE, Roger. Globalização e Educação: demonstrando a existência de uma "Cultura Educacional Mundial Comum" ou localizando uma "Agenda Globalmente Estruturada Para A Educação?”. Educação e Sociedade, Campinas, v. 25, n.87, p.423-460, maio/ago. 2004.

Disponível em: <http:/www.marxists.org/portugues/gramsci/1916/mes/ jornais.htm>. Acesso em: 20 set. 2011.

GRAMSCI, Antônio. Cadernos do cárcere: Maquiavel. Notas sobre o Estado e a política. Rio de Janeiro: Civilização Brasileira, 2000b.

GRAMSCI, Antônio. Cadernos do cárcere: os intelectuais; o princípio educativo; jornalismo. v. 2. Rio de Janeiro: Civilização Brasileira, 2000a.

GRAMSCI, Antônio. Intelectuais e a organização da cultura. São Paulo: Civilização Brasileira, 1999.

GRAMSCI, Antônio. Os jornais e os operários. Marxists Internet Archive, 2005.

IANNI, Octavio. O principe eletrônico. São Paulo, SP: Unicamp, 2000. [Online]. Disponível em: <http://www.juridicas.unam.mx/publica/librev/rev/ cconst/cont/4/art/art1.pdf>. Acesso em: 10 out. 2011. 
MORAES, Dênis. Comunicação, hegemonia e contra-hegemonia: a contribuição teórica de Gramsci. Revista Debates, Porto Alegre, v. 4, n. 1, p. 54-77, jan./jun. 2010.

NAIRDOF, Judith. La privatización del conocimiento público en universidades públicas. In GENTILI, Pablo; LEVY, Bettina (Org.). Espacio público y privatización del conocimiento: estudios sobre políticas universitarias en la América Latina. Buenos Aires: Clasco, 2005. p. 101-162.

RUBIM, Antonio A. C. Comunicação e política. São Paulo: Hacker, 2000.

SAVIANI, Dermeval. $\mathrm{O}$ trabalho como princípio educativo frente às novas tecnologias. In: FERRETI, Celso João; ZIBAS, Dagmar M. L.; MADEIRA, Felícia R.; FRANCO; Maria Laura P.B. (Org.). Novas tecnologias, trabalho e educação: um debate multidisciplinar. 3. ed. Cap. III. Petrópolis: Vozes, 1994, p. 151-168.

SILVA, D. F. Reflexôes sobre Educação, escola e mudanças no mundo do trabalho a partir de uma perspectiva crítica. In: FILHO, D. L. L. (Org.). Trabalho e formação humana: o papel dos intelectuais e da educação. Curitiba: Editora UTFPR, 2011, p. 85-104.

UNIVERSIDADE: a chave do futuro. Jornal da Globo. Rio de Janeiro, Rede Globo, 23-27 maio de 2011. Reportagem de TV.

VELLOSO, João Paulo dos Reis O Brasil e a economia do conhecimento. Rio de Janeiro: José Olympio, 2002. 


\section{Higher education, medias and knowledge: new news and old discourses}

\begin{abstract}
The series of reports University: the key to the future, presented in May 2011 on the Jornal da Globo national television news program serves as the basis for the discussions in this study. We present an analysis of this series, understanding that the communication media act as spokesmen for conservative Brazilian thinking. Gramscian concepts guide the analysis by locating the ideological disputes among the social groups in civil society, represented by the private apparatuses of hegemony, which includes the communication media. The study looks at the discussions about the role of education, particularly for meeting market demands and serving development, and the close tie between education and the economic sector; the tripartite structure of a good university; the public and private binomial; and the evaluation and ranking of universities. These themes 1express the constitution of a conservative consensus concerning the reconfiguration of higher education in Brazil.
\end{abstract}

Keywords: Higher Education. Communication Media. Gramsci, Antônio.

\section{Enseignement supérieur, médias et connaissance: neuves nouvelles et anciens discours}

\section{Résumé}

La série de rapports "Université: clé de l'avenir", exhibé au mois de mai 2011, dans le Jornal da Globo (journal télévisé Brésilien), c'est le record médiatique qui sert comme point de départ pour les discussions de cet étude. Nous présentons l'analyse de cette série, en comprenant que les médias agissent comme porteparole de la pensée conservatrice au Brésil. L'outil gramscien guide l'analyse situant différences idéologiques entre les groupes sociaux dans la société civile, représentés par des appareils privés de l'hégémonie, parmi eux, les médias. Cet étude passe par les discussions sur le rôle de l'éducation, en particulier quand il s'agit de répondre aux exigences du marché et du développement, dans l'étroite liaison entre l'éducation et le secteur économique; la structure du trépied pour une bonne université; le binôme public et privé; et l'évaluation et le classement des universités. Les thèmes soulignés expriment la constitution d'un consensus conservateur au sujet de la configuration de l'Enseignement Supérieur au Brésil.

Mots-clés: Enseignement Supérieur. Les médias. Gramsci, Antonio. 
Cezar Luiz De Mari

E-mail: cezardemari@uol.com.br

Lara Carlette Thiengo

E-mail: laracarlette@gmail.com

Recebido em: 4/11/2011

Versáo final recebida em: 20/1/2012

Aprovado em: 16/3/2012 